\title{
Strategies for Nurses in Antiretroviral Clinics to Mitigate Symptoms of Compassion Fatigue
}

\author{
Mercia Jane Tellie \\ https://orcid.org/0000-0002-7559-040X \\ University of South Africa \\ tellimj@unisa.ac.za
}

\section{Neltjie van Wyk}

https://orcid.org/0000-0002-9456-2121

University of Pretoria, South Africa

neltjie.vanwyk@up.ac.za

\author{
Ronell Leech \\ https://orcid.org/0000-0002-6088-2717 \\ University of Pretoria, South Africa \\ ronell.leech@up.ac.za
}

\section{Abstract}

Compassion fatigue has a negative impact on the well-being of healthcare professionals. Compassion fatigue affects nurses physically, emotionally and psychologically, as well as their behaviour towards others. Factors that increase nurses' risk to develop compassion fatigue include an overwhelming workload, being a secondary witness to their patients' traumatic experiences, emotional involvement with patients, especially children, lack of managerial support, and dealing with the deaths of their patients. The purpose of this paper is to describe strategies that nurses who work in antiretroviral (ARV) clinics use to mitigate the symptoms of compassion fatigue. A qualitative single embedded case study, utilising semi-structured interviews to collect data in ARV clinics in a tertiary hospital in the Gauteng province of South Africa was used. The process of content analysis as described by Elo and Kyngäs was utilised to analyse the data. The knowledge gained from the research findings contributed towards the identification of strategies that nurses use to prevent and manage compassion fatigue - strategies such as debriefing, management support, psychological support, self-care, collegial support, and celebrating patients' lives. If compassion fatigue is not recognised early and managed properly, it will have a negative impact on the quality of care and can result in an increase in the turnover rate of staff - therefore the need for strategies that will mitigate the symptoms of compassion fatigue.

Keywords: antiretroviral clinics; collegial support; compassion fatigue; managerial support; psychological support; self-care strategies

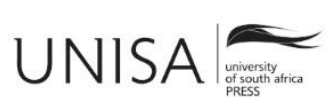




\section{Introduction and Background}

South Africa carries the largest burden of the HIV epidemic globally, with 7.1 million people living with HIV (Motsoaledi 2018, 11) and 3.39 million people on antiretroviral (ARV) treatment as at mid-2015 (Johnson, Dorrington and Moolla 2017, 53). The HIV/AIDS epidemic remains a major health problem in South Africa and the cause of premature deaths and morbidity (Quan and McCarthy 2018, 88). The country also has the largest ARV treatment programme globally, which is helpful to reach the 90-90-90 target set by UNAIDS in 2013. The aim of the 90-90-90 target is that by 2020, 90 per cent of people living with HIV should know their HIV status, 90 per cent of people diagnosed with HIV should receive ARV treatment, and 90 per cent of people on ARV treatment should have viral suppression. South Africa shows variable progress pertaining to these targets, as of October 2017 the progress reported pertaining to the 90-90-90 target stated that 86 per cent of South Africans know their HIV status, 65 per cent of the population tested for HIV, and 81 per cent of people diagnosed with HIV have started ARV treatment (Motsoaledi 2018, 11). The above strategy has led to an improvement in the life expectancy of South Africans with people living beyond 62 years, and the mother-to-child transmission has dropped to 2 per cent and results in more children surviving. However, the vulnerability to HIV infection among adolescent girls and young women is still a concern. Fortunately, stakeholders have committed to programmes aimed to protect, empower and capacitate young women such as the "She Conquers Campaign" (South African National AIDS Council Trust 2017/2018, 8).

Owing to the large number of patients who require ARV treatment, nurses' workload has increased. The nurse-initiated management of ARV treatment (NIMART) was implemented by the Department of Health in 2010 to decentralise the ARV treatment programme to primary healthcare clinics, making nurses responsible for initiating ARV treatment to patients who are HIV positive. Nurses who work at these decentralised facilities are overburdened with large patient numbers and long working hours with a high demand for primary healthcare services (Visser et al. 2018,1). Working in these demanding circumstances cause nurses to feel overwhelmed and frustrated, and their stress levels increase because they feel they are not well prepared to take on the extra responsibility, resulting in an increase in their vulnerability to develop compassion fatigue (Bam and Naidoo 2014, 14; Berg and Nilsson 2015, 10). In a study done by Tellie (2016) on compassion fatigue among nurses who work in ARV clinics, the findings revealed that the participants used several strategies that helped them to cope in the workplace of which collegial support was regarded as valuable, followed by selfcare, and celebrating their patients' lives. However, the nurses also expressed a need for debriefing and psychological and managerial support. Many studies explored and described compassion fatigue among nurses working in different health disciplines such as oncology, emergency care, mental healthcare, general healthcare and midwifery. However, this article aims to reveal a greater understanding of strategies that nurses working in ARV clinics can use to mitigate the symptoms of compassion fatigue. 


\section{Problem Statement}

Nurses who work in ARV clinics become witness to the suffering of their patients that makes them vulnerable to develop compassion fatigue, which has a negative effect on their ability to feel compassion towards their patients (Loolo 2016, 32-34; Turgoose and Maddox 2017, 172). By listening to patients' traumatic stories, the negative emotions of patients might be absorbed, and, unfortunately, not all nurses are equipped to handle these situations in such a way that they do not become secondarily affected by the trauma their patients face (Figley 1995, 15). There is a need for strategies to mitigate compassion fatigue as compassion fatigue has a negative effect on the wellbeing of nurses, rendering them incapable of providing quality care (Lachman 2016, 278).

Thus, the need arises for strategies to mitigate the negative effects of compassion fatigue because nurses who are affected will provide sub-standard nursing care to their patients or leave the profession and this will exacerbate the crisis of understaffed ARV clinics.

\section{Aim of the Paper}

The aim of this paper is to identify and describe strategies that nurses who work in ARV clinics can use to prevent and manage compassion fatigue.

\section{Objective}

The objective of this paper is to propose strategies that nurses who work in ARV clinics can use to mitigate the symptoms of compassion fatigue.

\section{Research Questions}

The research questions that guided this study were: (1) What strategies can nurses who work in ARV clinics use to prevent and manage compassion fatigue? (2) What strategies can nurses who work in ARV clinics use to mitigate the symptoms of compassion fatigue?

\section{Definitions of keywords}

Antiretroviral clinic: Any setting in a hospital, outpatient department or primary healthcare clinic that provides ARV treatment to patients who are eligible to receive ARV treatment.

Compassion fatigue: According to Zhang et al. $(2018,1)$, compassion fatigue "is the progressive cumulative outcome of prolonged, continuous, and intense contact with 
patients, self-utilization, and exposure to multidimensional stress leading to compassion discomfort that exceed nurses' endurance level".

Compassion satisfaction: The joy experienced by healthcare professionals when contributing positively to the well-being of patients (Turgoose and Maddox 2017, 172).

Human Immunodeficiency Virus (HIV): The virus that causes HIV infection. HIV infects and destroys cells of the immune system causing an individual to become more prone to infections (CDC 2019).

Nurse: In this study, a nurse is a person registered in terms of the Nursing Act, 2005 (Act No. 33 of 2005) in a category under Section 31(1), according to Regulation R.425 and R.683 or enrolled according to Regulation R.2175 (SANC 2005).

\section{Theoretical Framework of the Study}

The study was based on Watson's Caring Theory (1988), Erikson's Human Developmental Theory (1997) and Figley's Compassion Fatigue Etiological Model (2002). These two theories and model provided a lens to support the researcher's understanding of the external reality of compassion fatigue among nurses working in ARV clinics. Nursing is a caring profession and nurses are mandated to provide compassionate care and support to their patients to achieve or maintain health (Watson 1988). In Watson's Caring Theory (1988) it is stated that caring requires emotions, concerns, attitudes and a desire to relieve the suffering of patients. Nurses have intentions to relieve their patients' suffering by being compassionate towards them and this cause them to become empathetically involved with their patients with stressful consequences that make them vulnerable to compassion fatigue. Being empathetic towards their patients place them at risk of developing compassion fatigue (Figley 1995).

Nurses should engage in a helping-trusting relationship when caring for patients (Watson 1988). Entering into a helping-trusting relationship requires nurses to have developed a sense of trust that they have developed within the first year of life (Erikson 1997). A sense of trust will cause nurses to have faith and hope that they will positively contribute towards the healing of their patients. However, being in a relationship with HIV-positive patients causes nurses to be exposed to the traumatic events of their patients. As they listen to their patients' stories, they absorb the negative energy that may cause them to become secondary traumatised (Figley 1995). Being traumatised shatters nurses' assumptions of trust and can affect their sense of hope (Erikson 1997). Nurses feel hopeless because there is no cure for HIV. The incidence rate of the HIV epidemic is continually rising and having to care for large numbers of patients make nurses feel overwhelmed, and this increase their risk to develop compassion fatigue. 
Compassion fatigue has a negative effect on the caring relationship between nurses and their patients because nurses may either overidentify with their patients or distance themselves from their patients. The relationships between nurses and their colleagues are also negatively affected, hence the need to identify strategies to mitigate the symptoms of compassion fatigue. Being aware of compassion fatigue and the proposed strategies can help to prevent and manage it and contribute towards healthy nurses and improved quality of care for HIV-positive patients.

\section{Research Methodology}

The researcher adopted Yin's (2014) approach for conducting a single case study with embedded units of analysis, namely adult, antenatal and paediatric ARV clinics within a tertiary hospital in South Africa. The subunits provided more opportunities for extensive analysis, thereby enhancing insight into the single case.

\section{Research Setting}

The study was conducted in a tertiary hospital in the Gauteng province that provides comprehensive care to adults, children and pregnant women who are HIV positive. The healthcare services provided in the adult and paediatric ARV clinics were doctorcentred and the services were provided from Mondays to Fridays. However, the antenatal ARV clinic operated only on Fridays and the healthcare services were provided by doctors and registered nurses. The ARV clinics were well resourced since they operated within the outpatient department of a specialised hospital. The three ARV clinics had an operational manager and several doctors and medical students who rotated in the clinic. The adult clinic had three registered nurses and one enrolled nurse, while the paediatric ARV clinic had two professional nurses. The two registered nurses who worked in the antenatal ARV clinic were employed by a non-governmental organisation (NGO) that provided support to the clinic.

\section{Population and Sampling}

The population consisted of seven nurses who worked in a specific ARV clinic on a permanent basis for longer than six months and who were willing to participate in the study. Six registered nurses (RNs) and one enrolled nurse (EN) participated in the study.

\section{Data Collection}

Data collection took place through semi-structured interviews and the perusal of official documents and field notes to allow for triangulation. Informed consent was obtained from the participants before conducting the interviews. The interviews were held over two days in October 2009 using an interview guide, which covered open-ended questions on aspects of trust, despair, hope, caring for patients who are HIV positive, stress, compassion, compassion fatigue, empathy, feelings towards patients who are HIV positive, and the role of nurses in ARV clinics. Each interview lasted 
approximately one hour, and field notes were captured soon after the interviews to enhance the richness of the data. With the permission of the participants all interviews were tape-recorded to provide a more accurate rendition of the interviews.

\section{Analysis}

The researcher transcribed the interviews verbatim, and the data were analysed using the inductive content analysis as described by Elo and Kyngäs (2008) with the help from supervisors. The transcripts were read several times, and then the data were grouped into subcategories with similar events and incidents as categories. The categories were named, and groups of categories were listed together as main categories and themes. Two independent coders who signed a confidentiality agreement were used to verify that all relevant themes, categories and subcategories have been identified. Consensus was reached among the researcher and the independent coders.

\section{Trustworthiness}

The criteria of transferability, credibility, dependability, confirmability and authenticity as described by Lincoln and Guba (1985) were employed to achieve trustworthiness.

Detailed descriptive information that allows readers to decide whether the research findings can be applied to new situations was used. Transferability was achieved through a process of triangulation using individual interviews and field notes, literature control and two independent coders.

To achieve credibility, the researcher stayed in the research environment during the data collection, and multiple data collection sources were used while two independent qualitative researchers verified all the themes, categories and subcategories identified during the analysis. The data collection, analysis and interpretation of the data were densely described to provide information to show how repeatable the study might be. The researcher's supervisors checked the research plan and the implementation thereof.

To ensure that the information provided, and the data interpreted were authentic, the researcher kept an audit trail, raw data, an interview guide, recorded interviews, written field notes, survey results, the analysed data, and the process notes. The transcripts used are kept in a master file under lock and key for 15 years as evidence for auditors.

To enhance authenticity, an interview guide was used during interviews and field notes were taken regarding the participants' emotions and other non-verbal cues expressed during the interviews. 


\section{Ethical Considerations}

The research ethics committee of a university in the Gauteng province approved the study and the Gauteng Health Department and CEO of the tertiary hospital granted permission to conduct the study. Ethical considerations in this study included informed consent, voluntary participation, confidentiality, and the right of participants to withdraw from the study without prejudice. The privacy of the participants and the hospital was respected, and the participants' names and the institution's identity were kept confidential in all reports. Informed consent was obtained from all the participants before the data collection. The nature of the study, benefits of participation as well as risks involved were explained to all participants. The participants were also informed that participation was voluntarily, all information provided will be kept confidential and they can withdraw from the study at any time without any prejudice against them.

\section{Description of Participants}

Table 1: Summary of characteristics of participants

\begin{tabular}{|lllllll|}
\hline Participant & Employer & Clinic & Age & $\begin{array}{l}\text { Category } \\
\text { nurse }\end{array}$ & $\begin{array}{l}\text { Years } \\
\text { in } \\
\text { clinic }\end{array}$ & $\begin{array}{l}\text { Trained in } \\
\text { HIV care and } \\
\text { management }\end{array}$ \\
\hline 1 & Public hospital & Adult & 64 & RN & 6 & Yes \\
\hline 2 & NGO & Antenatal & 45 & RN & 3 & Yes \\
\hline 3 & Public hospital & Pediatric & 43 & RN & 11 & Yes \\
\hline 4 & Public hospital & Pediatric & 48 & RN & 3 & Yes \\
\hline 5 & Public hospital & Adult & 51 & RN & 6 & Yes \\
\hline 6 & Public hospital & Adult & 47 & EN & 5 & No \\
\hline 7 & NGO & Antenatal & 41 & RN & 3 & Yes \\
\hline
\end{tabular}

\section{Results}

Seven nurses participated in the study; six registered nurses and one enrolled nurse. Two RNs were employed by an NGO worked in the antenatal ARV clinic and the other nurses were employed by the Department of Health. Two RNs worked in the adult clinic, two in the antenatal clinic, two in the paediatric clinic, and one EN in the adult ARV clinic. The number of years they worked in these clinics ranged from three to eleven years. They were all females and their ages ranged between 41 to 64 years. All the registered nurses were trained in HIV/AIDS care and management.

This paper emanates from a larger doctoral study in which three themes, five categories and 12 subcategories emerged from the data collected. However, this paper will focus on one theme, two categories and six subcategories (see Table 2). 
Table 2: Summary of theme, categories and subcategories

\begin{tabular}{|l|l|l|}
\hline Theme & Categories & Subcategories \\
\hline $\begin{array}{l}\text { Strategies to prevent } \\
\text { and manage } \\
\text { compassion fatigue }\end{array}$ & Category 1 & $\begin{array}{l}\text { Debriefing } \\
\text { Preferred support from } \\
\text { management }\end{array}$ \\
\cline { 2 - 3 } & $\begin{array}{l}\text { Managerial support } \\
\text { Category 2 }\end{array}$ & Psychological support \\
& Personal strategies & Collegial support \\
\hline
\end{tabular}

\section{Theme: Strategies to Prevent and Manage Compassion Fatigue}

For this paper, only one theme will be discussed, namely strategies to prevent and manage compassion fatigue. It will be divided into two categories: (a) preferred support from management; and (b) personal strategies.

\section{Category 1: Preferred Support from Management}

The importance of support from management was perceived as essential to help nurses cope. The support identified includes debriefing, the employment of more staff, and psychological support.

Caring for HIV-positive patients is demanding and can evoke significant stress, and the participants expressed a need for debriefing to be given an opportunity to talk about issues:

... debriefing ... so that people can talk about their issues ... (P1)

The counselling of patients was perceived as burdensome and invoked anxiety. However, the participants felt that debriefing can provide them with an opportunity to talk:

... we are also being taken as counsellors ... debriefing is important to us as staff ... (P4)

The participants felt that management should recognise that they are not doing well and should therefore organise regular debriefing sessions:

... they [management] can say that we see that you are not doing well, what if we organise a debriefing but ... the intervals [between debriefing sessions] must not be too long ... (P1)

The participants felt that the employment of more staff will help them cope with the workload. They expressed a need for more staff: 
... from management, if we can get the support of them bringing more people to come and help us. (P3)

The need for the appointment of more doctors was also expressed:

If we can get more doctors ... it will make our lives easier ... (P3)

Non-nursing duties caused the nurses to spend less time with their patients. The amount of paperwork caused the participants to feel overwhelmed and they felt another category worker can do it:

$\ldots$ the more job is the clerical, writing in register and stats. Somebody else can do that

... [management to] employ more people ... (P6)

The participants felt that there are opportunities available to update their knowledge on HIV/AIDS. However, not everybody is given a chance to attend workshops and symposiums:

... we don't attend workshops anymore, symposiums ... They [management] must make that everybody who is working here [ARV clinic] must benefit from those [workshops and symposiums] ... (P5)

The participants expressed a need to be recognised by management:

$\ldots$ small thing that would make you feel valued ... from our managers ... (P7)

Some participants highlighted the support from doctors that helps them to manage difficult patients:

... with our doctors, we have these meetings for case discussion sessions ... we discuss the cases, the challenges and it gives us strength. (P7)

Family support is essential. The participants talk to their families and it helps them to cope:

... talking to your family, it makes you feel better ... (P7)

\section{Category 2: Personal Strategies}

Nurses who work in ARV clinics care for large numbers of traumatised HIV-positive patients, and face mortality daily, which increases their vulnerability to develop compassion fatigue. The participants revealed that they must also care for themselves, and developing coping skills helps them to mitigate the negative effects of compassion fatigue. The participants were not aware of any wellness programmes available to them and no debriefing facilities were available. They indicated that in order to cope they use collegial support, self-care and celebrate their patients' lives. 
The participants also support each other, which helps them to cope:

... working with colleagues it helps because sometimes when you care for people and you feel there is something that disturbed you ... we discuss about it and that brings upon relief to you ... (P7)

When having a bad day, talking to a colleague brings relief:

... if you are having a bad day and you talk to one of your colleagues, it does help; you get some form of relief. (P2)

Colleagues provide advice when faced with challenging situations:

...sometimes you meet with your colleagues and ... the challenges you had in the week ... will tell you how to cope ... (P7)

By talking to each other the participants realise that others are facing the same problems:

... and you'll feel that I'm not alone ... in suffering or experiencing ... it's like you thought your situation is only overwhelming to you when it's not only you, other people too are facing such, ... situation. (P7)

One participant reported talking to colleagues in the tearoom after the death of a patient and they provided an informal debriefing:

... after that week (when one of the children died) that we have difficulty, but we got time to speak in the tearoom ... talk about it with colleagues ... that's the way we destress ... (P3)

The participants realised the importance of self-care as a form of protecting themselves against stress:

... try going to the gym ... that is de-stressing ... (P4)

Some participants reported that they believe in a higher being and that praying helps to relieve stress:

... prayer helps me a lot ... I go to church on Sunday after experiencing all the stress during the week ... (P1)

One participant also advises her patients to pray:

... I tell my patients to also pray ... (P1)

It is essential to forget about work when off duty, and the participants described strategies they use to break away: 
... watch television; try to forget about work, maybe chill with some friends. (P4)

One participant just shuts down:

... I shut down ... forget about work ... (P4)

The participants did something very different and celebrated their patients' lives with a candle-lighting ceremony on World AIDS Day:

... sometimes organising some things here in the clinic which we enjoy; like celebrating

World AIDS Day with our patients and having that moment of feeling okay. Just mingling with people and talking to people about how you feel ... (P1)

\section{Discussion}

In this study, the nurses identified various strategies that they can use to mitigate the negative effects of compassion fatigue. Management and psychological support are very important for nurses to cope in ARV clinics. The participants indicated the current strategies they are using to mediate stress and mitigate the negative effects of compassion fatigue with the most valued strategy being talking to a colleague or family member, having an informal debriefing among themselves, mentoring, breaking away from work, self-caring, celebrating their patients' lives, and praying. Three main interventions were identified as strategies, namely management support, psychological support, and debriefing.

Dealing with compassion fatigue requires deliberate action from managers to create an environment that is conducive to the well-being of nurses as well as patients. There was an outcry from the participants for support from management to employ more staff, to organise regular debriefing sessions, for recognition and for training in HIV/AIDS. Literature describes several ways in which managers can provide support to staff that will mitigate compassion fatigue such as training in HIV/AIDS and compassion fatigue to create awareness, the provision of the necessary resources to do the work, and the creation of personal and professional development opportunities (Bam and Naidoo 2014, 14; Haber, Roby, and High-George 2011, 548). Managers should acknowledge that working in ARV clinics increases nurses' vulnerability to develop compassion fatigue and they should explore ways to protect the nurses from the harmful effects of working with traumatised patients (Yoder 2010, 196). Management can also provide support in creating an environment that increases job satisfaction that will in turn result in compassion satisfaction that acts as a buffer against compassion fatigue (Schmidt and Haglund 2017, 319).

Feeling supported at work and being able to develop personally and professionally will result in a positive perception of the self and increase job satisfaction that will in turn help to mitigate compassion fatigue. However, the perception of skill deficits can add 
to stress levels that will increase vulnerability to compassion fatigue (Drury et al. 2014, 524; 527). Thus, to help nurses to keep abreast with new developments in the HIV/AIDS field, managers should include HIV/AIDS training in the nurses' training plan that will enable them to maintain high quality care (Bam and Naidoo 2014, 11; Berg and Nilsson 2015, 10). Feeling overwhelmed by their work can increase nurses' stress levels and vulnerability to compassion fatigue (Figley 1995, 12). The participants also requested more staff to help with non-nursing duties such as filing and keeping statistics. Nurses are overwhelmed by the amount of paperwork, long queues, huge workload and difficult patients (Rapp 2012,73; Visser et al. 2018, 1). Management should employ people to do the clerical work to decrease nurses' involvement with the paperwork so that they will have more time for their patients.

Talking to colleagues after the death of a patient served as an informal debriefing and helped nurses to cope. Exposure to multiple deaths in a short period can increase nurses' risk to develop compassion fatigue (Gerow et al. 2009, 127). The effects of cumulative grief may cause nurses to distance themselves emotionally from patients or to overidentify with their patients, which makes them vulnerable to develop compassion fatigue (Boyle 2011,8). Nurses do grieve over the deaths of their patients. Thus, managers should establish a bereavement support programme that focuses on providing support to nurses and that enables them to find closure when their patients die (Fetter 2012, 560). Psychological support can lessen compassion fatigue (Hee and Kyung $2012,50)$ and can be provided in several ways through on-site counselling and the establishment of support groups, debriefing facilities, and bereavement support. If possible, nurses should be allowed to attend a patient's funeral or memorial service, where they can participate in bereavement rituals and create sympathy cards for the family or memory tree of the deceased patient (Aycock and Boyle 2009, 186; Boyle $2011,8)$. The participants also expressed a need for regular debriefing to be organised by managers. Harris and Griffin $(2016,85)$ state that debriefing can relieve tension and emotional adverse effects of trauma after intense periods of caring and can prevent compassion fatigue (Yoder 2010, 191; 196). Informal debriefing can be formalised by starting up peer support groups as a strategy to mitigate compassion fatigue (Masters, Stillman, and Spielmans 2007, 11).

Some participants expressed the need to feel valued and recognised for the contributions they make in the ARV clinic. According to O'Neil (2015), to reward and recognise staff act as a buffer against stress. To fulfil the nurses' need to be recognised, managers should establish a reward system that recognises outstanding achievements - for example, a best-nurse-of-the-month award for contributing to the well-being of patients. Such rewards and recognition will increase nurses' sense of job satisfaction, which in turn will help to prevent compassion fatigue (Kelly, Runge, and Spencer 2015, 527).

In the context of each participant's experience, five strategies to reduce stress and to mitigate the negative effects of compassion fatigue were used by the nurses in the absence of formal workplace strategies or interventions, namely break away from work, 
collegial support, self-care, praying, and celebrating their patients' lives. The participants placed high value on collegial support to help them cope - they would talk in the tearoom and give each other advice on how to deal with the challenges they face. The support they provide to each other is context specific and can lessen compassion fatigue (Bam and Naidoo 2014, 8; Rapp 2012, 79; Aycock and Boyle 2009, 188). Since collegial support was highly valued by the participants, managers can encourage nurses to start peer-support groups that can be facilitated by pastoral care counsellors. During these support group meetings the nurses should be encouraged to talk about issues that frustrate them and to share their experiences with their patients (Lachman 2016, 278).

Another strategy that helped to reduce the participants' stress was the support from doctors during weekly case study meetings held to discuss difficult cases. Clinical supervision and mentoring from peers can reduce nurses' stress especially in situations where they feel underprepared to tackle certain tasks (Drury et al. 2014, 527). Managers can, with the help of doctors, start journal clubs or case discussion meetings as a process of continuous education to transfer skills among healthcare workers on how to manage difficult HIV-positive cases, with the aim to improve patients' outcomes (Bam and Naidoo 2014, 16). Such platforms can also be used to explore how caring for HIVpositive patients affects healthcare workers and to share strategies that help them to relieve stress (Haber, Roby, and High-George 2011, 548).

The participants realised the importance of self-care as participation in self-care is the cornerstone of compassion fatigue prevention (Hooper et al. 2010, 423). As part of selfcare, the participants joined a gym to engage in exercise, they spent time with their families and some relaxed with friends or just watched television. Rapp $(2012,80)$ states that effective internal coping strategies such as discussing issues with others and taking a break away from work should be recommended to healthcare professionals who work in the HIV/AIDS field to decrease chronic fatigue, frustration and depression. Thus, disengagement from patients' deep pain can help to reduce compassion fatigue (Loolo 2016, 106-107). Managers should create an environment that encourages nurses to participate in self-care activities that will nurture and revitalise them.

Some participants reported that by being spiritual, reading the Bible, praying and even praying for their patients helped them to cope. Nurses' spiritual foundation and religious beliefs help them to cope and, when feeling hopeless because they cannot do anything for their patients, they pray for them (Kerr et al. 2011, 488; 489). Being spiritual or religious and spending time with a pastor help the nurses to focus on other things and help them to heal - it may protect nurses from the negative effects of grief and compassion fatigue and help to reduce stress levels (Aycock and Boyle 2009, 186; Yoder 2010, 194). Thus, if spirituality and prayers help nurses to de-stress, managers can establish pastoral care where they can refer the nurses for support (Bam and Naidoo 2014, 14; Kerr et al. 2011, 488). 
Creating opportunities to celebrate the lives of patients who died can be therapeutic. The participants used World AIDS Day to remember their patients who have passed away by organising a candle-lighting ceremony. Coping with the death of a patient is not easy. Bereavement debriefing can be used as an approach to support nurses in managing their grief (Keene et al. 2010, 185). To assist nurses while grieving for their patients, managers can establish bereavement support programmes by organising patient celebration events, memorial services for patients, allowing the nurses to attend funerals if they wish to or encouraging nurses to start a memory tree of patients in the ward which will assist them to find closure (Aycock and Boyle 2009, 186).

\section{Conclusion}

This paper proposed strategies that nurses can use to reduce stress and mitigate the effects of compassion fatigue. Managers should acknowledge that nurses who work in ARV clinics are at risk of developing compassion fatigue and should explore ways to protect them. To mitigate the negative effects of compassion fatigue, managers should provide psychological support through the establishment of regular debriefing sessions, peer support groups, pastoral care, and bereavement support programmes. Nurses should be encouraged to engage in self-care and practice self-compassion.

\section{Recommendations for Practice}

Awareness is the key to preventing compassion fatigue. Programmes that increase nurses' awareness of compassion fatigue and bereavement support should be implemented. Managers should enhance and build nurses' resilience. Resilience can be built through self-nurture, self-care, detachment, a sense of satisfaction and social support which act as protective factors against compassion fatigue. The aim of strategies should be to preserve nurses' interpersonal competencies and empathetic ability to ensure quality care to patients.

\section{Recommendations for Future Research}

Future studies could explore the effectiveness of the proposed strategies to mitigate compassion fatigue. Further research on compassion fatigue among nurses in primary healthcare settings where most HIV-positive patients are cared for is recommended, and male nurses should be included in the study.

\section{Limitations of the Study}

The study took place in one tertiary hospital and in one province only, and therefore the findings cannot be generalised. Another limitation of the study might be that all the 
participants were female. It is possible that compassion fatigue manifests differently in men; thus, the findings cannot be generalised for male nurses.

\section{References}

Aycock, Nancy, and Deborah A. Boyle. 2009. "Interventions to Manage Compassion Fatigue in Oncology Nurses.” Clinical Journal of Oncology Nursing 13 (2): 183-91. https://doi.org/10.1188/09.CJON.183-191.

Bam, Nokwanda E., and Joanne R. Naidoo. 2014. "Nurses Experiences in Palliative Care of Terminally-Ill HIV Patients in a Level 1 District Hospital.” Curationis 37 (2): 1-19. https://doi.org/10.4102/curationis.v37i1.1238.

Berg, Malin, and Lina Nilsson. 2015. "Nurses Experiences of Caring for Patients with HIV/AIDS in Dar es Salaam.” Bachelor's thesis, Umeå University Hospital. Accessed 10 January 2016. http://www.diva-portal.se/smash/get/diva2:856837/FULLTEXT01.pdf.

Boyle, Deborah A. 2011. "Countering Compassion Fatigue: A Requisite Nursing Agenda." Online Journal of Issues in Nursing 16 (1): 1-11.

CDC (Centers for Disease Control and Prevention). 2019. “About HIV/AIDS.” Accessed 30 August 2019. https://www.cdc.gov/hiv/basics/whatishiv.html.

Drury, Vicky., M. Craige, K. S. Frances, K. Aoun, and D. G. Hegney. 2014. “Compassion Satisfaction, Compassion Fatigue, Anxiety, Depression and Stress in Registered Nurses in Australia: Phase 2 Results.” Journal of Nursing Management 22 (4): 519-531. https://doi.org/10.1111/jonm.12168.

Elo, Satu, and Helvi Kyngäs. 2008. “The Qualitative Content Analysis Process.” Journal of Advanced Nursing 62 (1): 107-115. https://doi.org/10.1111/j.1365-2648.2007.04569.x.

Erikson, Erik H. 1997. The Life Cycle Completed. New York: W.W. Norton.

Fetter, Katrina L. 2012. "We Grieve too: On Inpatient Oncology Unit's Intervention for Recognising and Combating Compassion Fatigue." Clinical Journal Oncology Nursing 16 (6): 559-61. https://doi.org/10.1188/12.CJON.559-561.

Figley, Charles R. 1995. Compassion Fatigue: Coping with Secondary Traumatic Stress Disordering those who Treat the Traumatized. New York: Brunner/Mazel.

Figley, Charles R. 2002. “Compassion Fatigue: Psychotherapists' Chronic Lack of Self Care.” Psychotherapy in Practice 58 (11): 1433-44.

Gerow, I., P. Conejo, A. Alonzo, N. Davis, S. Rodgers, and E. W. Domain. 2009. "Creating a Curtain of Protection: Nurses' Experiences of Grief following Patient Death.” Journal of Nursing Scholarship 42 (2): 122-9. https://doi.org/10.1111/j.1547-5069.2010.01343.x. 
Haber, Daniel B., Jini L. Roby, and Lauren D. High-George. 2011. "Stigma by Association: The Effects of Caring for HIV/AIDS Patients in South Africa." Health and Social Care in the Community 19 (5): 541-9. https://doi.org/10.1111/j.1365-2524.2011.01002.x.

Harris, Chelsia, and Mary T. Q. Griffin. 2015. "Nursing on Empty: Compassion Fatigue Signs, Symptoms, and System Interventions.” Journal of Christian Nursing 32 (2): 80-87. https://doi.org/10.1097/CNJ.0000000000000155.

Hee, Yang Y., and Kim Jong Kyung. 2012. "A Literature Review of Compassion Fatigue in Nursing.” Korean Journal of Adult Nursing 24 (1): 38-51. https://doi.org/10.7475/kjan.2012.24.1.38.

Hooper, C., J. Craig, D. R. Janvrin, M. A. Wetsel, E. Reimels, A. Greenville, and S. C. Clemsen. 2010. "Compassion Satisfaction, Burnout, and Compassion Fatigue among Emergency Nurses compared with Nurses in other Selected Inpatient Specialities.” Journal of Emergency Nursing 36 (5): 420-7. https://doi.org/10.1016/j.jen.2009.11.027.

Johnson, Leigh., F. Rob, E. Dorrington, and Haroon Moolla, 2017. "Progress towards the 2020 Targets for HIV Diagnosis and Antiretroviral Treatment in South Africa." Southern African Journal of HIV Medicine 18 (1): 51-58. https://doi.org/10.4102/sajhivmed.v18i1.694.

Keene, Elizabeth A., N. Hutton, B. Hall, and C. Rushton. 2010. "Bereavement Debriefing Sessions: An Intervention to Support Health Care Professionals in Managing their Grief after the Death of a Patient." Pediatric Nursing 36 (4): 185-9.

Kelly, Lesly, Jody Runge, and Christina Spencer. 2015. "Predictors of Compassion Fatigue and Compassion Satisfaction in Acute Care Nurses." Journal of Nursing Scholarship 47 (6): 522-8. https://doi.org/10.1111/jnu.12162.

Kerr, Z. Y., E. L. Grafsky, K. Miller, and R. Love. 2011. "Stressors and Coping Strategies for HIV-Test Counsellors giving Rapid HIV-Test Results: An Exploratory Qualitative Study.” AIDS Patient Care and STDs. 25 (8): 483-91. https://doi.org/10.1089/apc.2011.0085.

Lachman, Vicki D. 2016. "Compassion Fatigue as a Threat to Ethical Practice: Identification, Personal and Workplace Prevention/Management Strategies." MEDSURG Nursing 25 (4): 275-8.

Lincoln, Yvonne S., and Egon S. Guba. 1985. Naturalistic Inquiry. Thousand Oaks: Sage.

Loolo, Maria A. 2016. “Compassion Fatigue and Crisis Worker's Attitude to Work.” PhD thesis, Walden University. 20 December 2016. https://scholarworks.waldenu.edu/cgi/viewcontent.cgi?article=2824\&context=dissertations 
Masters, Kevin S., Alexandra M. Stillman, and Glen I. Spielmans. 2007. "Specificity of Social Support for Back Pain Patients: Do Patients Care who Provides what?" Journal of Behavioral Medicine 30 (1): 11-19. https://doi.org/10.1007/s10865-006-9078-z.

Motsoaledi, Aaron. 2018. Policy on Research for Health in South Africa. Pretoria: Department of Health.

O’Neil, Stephanie. 2015. "The Cost of Caring: Compassion Fatigue in Hospice Nursing." Senior Honor Projects, Abstract. Accessed 24 July 2015. http://digitalcommons.uri.edu/cgi/viewcontent.cgi?article=1397\&context=srhonorsprog.

Quan, Vanessa, and Kerrigan McCarthy. 2018. "Communicable Diseases Surveillance and Outbreak Investigation in South Africa." South African Health Review 2018. 2018:87-98.

Rapp, Mackenzie K. 2012. “Occupational Stressors among Providers of HIV Prevention and Support Services.” Master's thesis, University of South Florida. Accessed 12 September 2015.

http://scholarcommons.usf.edu/cgi/viewcontent.cgi?article=5406\&context=etd.

SANC (South African Nursing Council). 2005. Nursing Act, 2005 (Act No. 33 of 2005). SANC.

Schmidt, Madeline, and Kristin Haglund. 2017. "Debrief in Emergency Departments to Improve Compassion Fatigue and Promote Resiliency.” Journal of Trauma Nursing 24 (5): 317-22. https://doi.org/10.1097/JTN.0000000000000315.

South African National AIDS Council Trust. 2017/2018. Annual Report 2017/2018. Pretoria: South African National AIDS Council Trust.

Tellie, Mercia J. 2016. “A Wellness Programme to Prevent and Manage Compassion Fatigue amongst Nurses Working in an Antiretroviral Clinic in a Public Tertiary Hospital.” PhD thesis, University of Pretoria.

Turgoose, David, and Lucy Maddox. 2017. "Predictors of Compassion Fatigue in Mental Health Professionals: A Narrative Review.” Traumatology 23 (2): 172-85. Accessed 10 August 2018. https://doi.org/10.1037/trm0000116.

Visser, Chris A., J. E. Wolvaardt, D. Cameron, and G. J. O. Marincowitz. 2018. "Clinical Mentoring to Improve Quality of Care Provided at Three NIM-ART Facilities: A Mixed Method Study.” African Primary Health Care Family Medicine 10 (1): a1579. https://doi.org/10.4102/phcfm.v101.1579.

Watson, Jean. 1988. Nursing: Human Science and Human Care: A Theory of Nursing. New York: League for Nursing.

Yin, Robert K. 2014. Case Study Research: Design and Methods. 5th ed. London: Sage. 
Yoder, Elizabeth A. 2010. "Compassion Fatigue in Nurses.” Applied Nursing Research 23 (4):191-197. https://doi.org/10.1016/j.apnr.2008.09.003.

Zhang, Ying-Ying, C. Zhang, X. R. Han, W. Li, and Y. L. Wang. 2018. "Determinants of Compassion Satisfaction, Compassion Fatigue and Burnout in Nursing: A Correlative Meta-Analysis.” Medicine 97 (6): e11086. https://doi.org/10.1097/MD.000000000011086. 